\title{
Prognostic value of vascularity and vascular endothelial growth factor expression in non-small cell lung cancer
}

\author{
R Baillie, J Carlile, N Pendleton, A M Schor
}

\begin{abstract}
Aims-High expression of the angiogenic factor vascular endothelial growth factor (VEGF) in tumours has been found to be associated with poor prognosis in some studies, but not in others. The aims of this study were to determine the prognostic value of VEGF in operable non-small cell lung cancer (NSCLC) and its possible association with vascularity.
\end{abstract}

Methods-Sections from 81 NSCLC archival specimens were stained with antibodies to von Willebrand factor (vWF) and VEGF. Vascularity was measured by the average density of $\mathrm{VWF}$ positive vessels. VEGF expression in tumour cells was assessed by consensus of two independent observers according to three indices, namely: (1) percentage of area stained, (2) intensity of staining, and (3) final score (product of area and intensity).

Results-VEGF immunoreactivity was present in all tumours and adjacent normal lung tissue. None of the three VEGF indices was associated with vascularity or the clinical parameters examined. Mean survival times were shorter in patients with high VEGF expression, but the difference was not significant. This applied to the full cohort of patients, or when analysed separately according to tumour type or stage. However, high VEGF expression was associated with poor survival in patients with high vascularity $(p=0.02)$. VEGF had no discriminant value among patients with low vascularity. Vascularity had no prognostic value, except for late stage patients (UICC

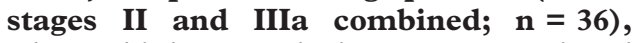
where high vascularity was associated with longer survival $(p=0.01)$.

Conclusions-VEGF on its own has no prognostic value in NSCLC, but may become a useful indicator when combined with vascularity. VEGF may play a physiological role in the normal lung. (F Clin Pathol 2001;54:116-120)

Keywords: non-small cell lung cancer; vascular endothelial growth factor; vascularity; prognosis

Solid tumours require a functional vasculature to grow and metastasise. To achieve this, tumour cells produce angiogenic factors that induce the formation of new blood vessels from the pre-existing vasculature. ${ }^{1}$ Vascular endothelial growth factor (VEGF) is a specific endothelial mitogen, and a potent inducer of vessel permeability and angiogenesis in vivo. ${ }^{2}$ In animal studies, the inhibition of VEGF induced angiogenesis suppresses tumour growth, ${ }^{3}$ and neutralisation of VEGF in established tumours results in apoptosis of immature blood vessels. ${ }^{4}$

Both VEGF mRNA and protein are present in a variety of tumour types including lung carcinoma. ${ }^{2}$ In these tumours, high expression of VEGF in tissue sections has been found to be associated with poor prognosis in squamous cell carcinoma, ${ }^{56}$ non-small cell carcinoma, ${ }^{7-10}$ and stage I adenocarcinoma. ${ }^{11}$ However, other studies showed that VEGF had no prognostic value in non-small cell carcinoma. ${ }^{12}{ }^{13}$ The prognostic value of VEGF concentrations in the serum of patients with lung cancer is also controversial: high expression has been associated with poor prognosis in small cell carcinoma, ${ }^{14}$ but had no prognostic value in non-small lung carcinoma (NSCLC) ${ }^{15}$ or various other types of lung tumours. ${ }^{16}$ VEGF expression and vascularity were directly correlated in some studies, ${ }^{8111718}$ but not in others. $^{1219}$

The aim of our study was to ascertain the prognostic value of VEGF expression in operable NSCLC and its possible association with vascularity. In previous studies, VEGF expression in histological sections has been determined using a variety of antibodies and quantification methods. In view of the lack of a standard protocol, we measured VEGF expression by the consensus of two independent observers using three methods or VEGF indices. The antibody used in our study has been compared previously to three other VEGF specific antibodies and was found to give stronger and more reproducible staining in mesotheliomas. ${ }^{20}$

\section{Materials and methods}

PATIENTS AND SPECIMENS

Eighty one patients were selected from consecutive operative resections for NSCLC performed at the Cardio-Thoracic Centre, Liverpool, UK. The patients exhibited similar survival characteristics to those from a larger series previously reported and to the general NSCLC population. ${ }^{21}$ Complete survival data were available for a follow up period of at least five years and only the most common NSCLC cell types-squamous cell or adenocarcinomas-were included. A representative formalin fixed tumour block was selected from each case on the basis of containing ample tumour areas and including tumour free margins. ${ }^{22}$ 
IMMUNOHISTOCHEMISTRY

VEGF was localised using a goat polyclonal specific antibody (IgG), raised against human rhVEGF $_{165}$ (Ab-293-NA; R\&D Systems, Oxon UK). Standard techniques were used after optimisation of staining. ${ }^{23}$ Briefly, histological sections $(6 \mu \mathrm{m})$ were dewaxed in xylene, rehydrated through graded alcohols, and incubated with $0.3 \% \mathrm{H}_{2} \mathrm{O}_{2}$ for 30 minutes to block endogenous peroxidase activity. Sections were pretreated by incubating with Protease XXIV (Sigma, Poole, Dorset, UK) at $1 \mathrm{mg} / \mathrm{ml}$ in phosphate buffered saline (PBS) for $20 \mathrm{~min}$ utes. Non-specific binding was blocked by incubating the sections for 30 minutes in $100 \%$ normal rabbit serum (SAPU, Law Hospital, Carluke, UK). The sections were then incubated overnight at $4^{\circ} \mathrm{C}$ with the primary antibody diluted $1 / 400$. Detection was carried out using biotinylated rabbit antigoat IgG and Vector Elite-ABC kit with $\mathrm{DAB}$ as detection substrate (all from Vector Laboratories, Peterborough, UK). Negative controls were incubated with normal goat IgG purified from serum (Dako). ${ }^{24}$

Blood vessels were stained with rabbit polyclonal anti-von Willebrand factor (vWF) antibody (Dako, High Wycombe, UK) as described previously. ${ }^{22}{ }^{25}$ Normal rabbit IgG (Dako) was used for negative controls.

MEASUREMENT OF VASCULARITY.

Vascularity was measured by the average microvascular density (a-MVD) of vWF positive vessels, as described previously. ${ }^{22}$ Briefly, a microscopic field of $0.5 \mathrm{~mm}^{2}$ was defined by an eyepiece graticule at $\times 200$ magnification. Any cell or cell cluster showing positive vWF staining and included within the field was counted as a single vessel. Eighteen random fields were counted across each section; the average value was calculated and expressed as vessels $/ \mathrm{mm}^{2}$.

\section{ASSESSMENT OF VEGF EXPRESSION}

The staining of VEGF in the tumour epithelium was assessed according to three indices, namely: (1) percentage of area stained, (2) intensity of staining, and (3) final score (product of area and intensity). The intensity of staining was graded by comparison with preselected calibration slides as: 1 , weak; 2 , moderate; and 3, strong. Some samples were considered intermediate (for example, 1.5) and used as such to obtain the final score. For the purpose of statistical analyses, intermediate intensity scores were rounded up to the next value. The assessments were carried out independently by two observers, based on the same calibration slides, and the final results were obtained by consensus. All laboratory tests were performed without knowledge of the clinical data.

\section{STATISTICAL ANALYSIS}

Because the data obtained were not normally distributed, all analyses were performed by non-parametric tests using SPSS software (version 8; SPSS Inc, Chicago, Illinios, USA). Kaplan-Meier and log rank tests were used for survival analysis. Details of the various tests used are given under the appropriate experimental sections. A 95\% level of confidence was used to define significant results.

\section{Results}

IMMUNOLOCALISATION OF VEGF IN LUNG TUMOURS AND ADJACENT NORMAL LUNG TISSUE All 81 specimens showed VEGF immunoreactivity intracellularly in tumour epithelial cells, as well as in some inflammatory cells, blood vessels, and fibroblasts within the tumour stroma. In the adjacent normal lung tissue, VEGF was present in the normal bronchial and glandular epithelium, smooth muscle cells, endothelial cells, and some fibroblasts and inflammatory cells. Heterogeneous patterns of staining were seen among the tumour cells, with positive and negative areas sometimes found next to each other. Figure 1 shows representative examples of normal lung and tumour.

RELATION BETWEEN VEGF EXPRESSION, VASCULARITY, AND CLINICAL PARAMETERS

Table 1 gives details of the patient characteristics, including tumour type, UICC tumour stage, and TNM status. Tumour volume was available for 47 of the 81 tumours.

VEGF expression in tumour cells was assessed by three indices (percentage, intensity, and final score) as described above. The VEGF percentage varied from 15 to 100 (median, 65). Of the 81 tumours examined, six showed an intensity of 1,51 an intensity of 2 , and 24 an intensity of 3 . The median intensity was 2 for all variables shown in table 1 . No significant
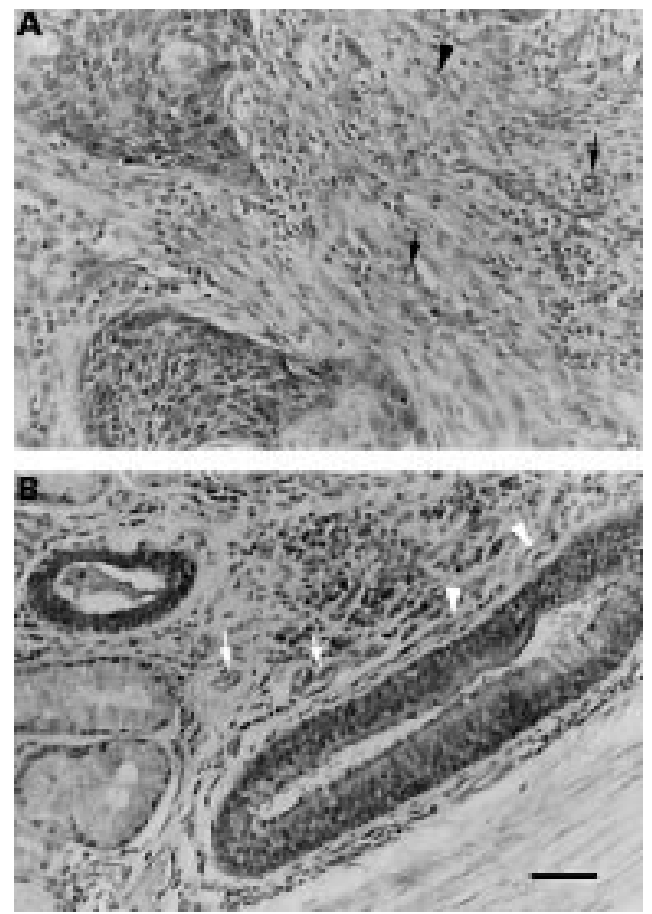

Figure 1 Immunolocalisation of vascular endothelial growth factor (VEGF) in non-small cell lung cancer and adjacent normal lung. (A) Squamous cell carcinoma: positive staining in tumour cells, stromal fibroblasts (arrowheads), and vessels (arrows). (B) Normal lung adjacent to tumour: positive staining in normal epithelial cells, inflammatory cells, fibroblasts (arrowheads), and vessels (arrows). Bar, $50 \mu \mathrm{m}$. 
Table 1 Patient characteristics and expression of vascular endothelial growth factor (VEGF)

\begin{tabular}{|c|c|c|c|c|c|c|c|}
\hline \multirow[b]{2}{*}{ Variable } & \multirow[b]{2}{*}{$n$} & \multicolumn{3}{|c|}{ VEGF percentage } & \multicolumn{3}{|c|}{ VEGF final score } \\
\hline & & Median & $I Q R$ & $p$ Value & Median & $I Q R$ & $p$ Value \\
\hline \multicolumn{8}{|l|}{$\begin{array}{l}\text { All patients } \\
\text { Age }\end{array}$} \\
\hline$<$ Median & 40 & 60.0 & 23.8 & \multirow[t]{2}{*}{0.404} & 122.5 & 78.8 & \multirow[t]{2}{*}{0.744} \\
\hline \multicolumn{6}{|l|}{ Sex } & & \\
\hline Male & 54 & 65.0 & 27.5 & \multirow[t]{2}{*}{0.948} & 127.5 & 66.9 & \multirow[t]{2}{*}{0.637} \\
\hline \multicolumn{6}{|l|}{ Tumour type } & & \\
\hline SCC & 62 & 65.0 & 26.2 & \multirow[t]{2}{*}{0.231} & 130.0 & 70.0 & \multirow[t]{2}{*}{0.571} \\
\hline Adeno & 19 & 50.0 & 30.0 & & 125.0 & 115.0 & \\
\hline \multicolumn{8}{|c|}{ Tumour volume } \\
\hline$<$ Median & 20 & 70.0 & 42.5 & \multirow{2}{*}{0.738} & 140.0 & 93.8 & \multirow{2}{*}{0.974} \\
\hline$\geqslant$ Median & 27 & 65.0 & 25.0 & & 140.0 & 70.0 & \\
\hline \multicolumn{8}{|c|}{ Tumour stage (UICC) } \\
\hline I & 45 & 60.0 & 30.0 & \multirow{3}{*}{0.212} & 125.0 & 85.0 & \multirow{3}{*}{0.504} \\
\hline II & 14 & 70.0 & 32.5 & & 140.0 & 63.7 & \\
\hline IIIa & 22 & 65.0 & 65.0 & & 135.0 & 75.6 & \\
\hline \multicolumn{8}{|l|}{$T N M-T$} \\
\hline $\mathrm{T} 1$ & 27 & 70.0 & 35.0 & \multirow{3}{*}{0.983} & 140.0 & 75.0 & \multirow{3}{*}{0.952} \\
\hline $\mathrm{T} 2$ & 44 & 62.5 & 28.8 & & 125.0 & 75.6 & \\
\hline T3 & 10 & 65.0 & 31.2 & & 135.0 & 63.8 & \\
\hline \multicolumn{8}{|l|}{$T N M-N$} \\
\hline No & 50 & 65.0 & 26.2 & \multirow{3}{*}{0.231} & 127.5 & 72.5 & \multirow{3}{*}{0.571} \\
\hline N1 & 15 & 70.0 & 40.0 & & 140.0 & 75.0 & \\
\hline $\mathrm{N} 2$ & 16 & 55.0 & 25.0 & & 120.0 & 69.4 & \\
\hline \multicolumn{8}{|l|}{ Outcome } \\
\hline Dead & 48 & 65.0 & 25.0 & \multirow[t]{2}{*}{0.543} & 120.0 & 71.9 & \multirow[t]{2}{*}{0.389} \\
\hline Alive & 33 & 55.0 & 32.5 & & 140.0 & 80.0 & \\
\hline
\end{tabular}

Two indices of VEGF are presented: percentage area stained and final score.

p Values were calculated by the Mann-Whitney U test or the Kruskal-Wallis test.

Outcome refers to the outcome five years after tumour resection.

Adeno, adenocarcinoma; IQR, interquartile range; SCC, squamous cell carcinoma.

association was found between any of the three VEGF indices and the clinicopathological characteristics of the patients (using MannWhitney, Kruskal-Wallis, and $\chi^{2}$ tests). The VEGF intensity was the least informative of the indices because most of the specimens showed an intensity score of 2 . However, the effects of intensity are reflected in the final score, which is the product of area and intensity. Table 1 summarises the VEGF percentage and VEGF final score results.
Vascularity was measured by the average microvascular density of vWF positive vessels. As reported previously for a larger group of patients ${ }^{22}$ there was no association between vascularity and the clinicopathological parameters examined (results not shown). The possible association between vascularity and VEGF indices was investigated by Spearman's rank order and $\chi^{2}$ (for VEGF intensity) tests. No significant correlations were found, with correlation coefficients ranging from 0.00 to 0.18 and $\mathrm{p}$ values larger than 0.35 .

ANALYSIS OF SURVIVAL.

Kaplan-Meier estimates of survival function according to vascularity and VEGF indices were analysed, splitting the data by both median and tercile values. Comparisons were made by the log rank test. Although there was a trend for improved survival in patients with low VEGF expression or with high vascularity, the differences were not significant for the 81 patients. Of the three VEGF indices, only VEGF percentage (when split by the median) reached a near significant $\mathrm{p}$ value $(\mathrm{p}=0.06)$. VEGF indices and vascularity were also analysed separately for patients with different tumour types (squamous cell carcinoma or adenocarcinoma) or UICC tumour stage (either I or II and IIIa combined). VEGF was not associated with survival in any of these cases $(p>0.11)$. In contrast, high vascularity was associated with longer survival $(p=0.01)$ in the combined group of stage II and IIIa patients $(n=36)$. Table 2 summarises these results.

Patients with high vascularity (median or above, $n=43$ ) and low vascularity (below median, $\mathrm{n}=38$ ) were then divided according to VEGF percentage (also divided by the median). Four groups were obtained: (1) high vascularity and high VEGF $(\mathrm{n}=23)$, (2) high

Table 2 Survival analyses according to vascular endothelial growth factor (VEGF) indices and vascularity

\begin{tabular}{|c|c|c|c|c|c|}
\hline Patients & Index & Division of index & $n$ & $\begin{array}{l}\text { Mean survival } \\
\text { (days) }\end{array}$ & $\begin{array}{l}p \text { Value } \\
\text { (log rank test) }\end{array}$ \\
\hline All & VEGF percentage & $\begin{array}{l}<\text { Median } \\
\geqslant \text { Median }\end{array}$ & 38 & $\begin{array}{l}1762 \\
1269\end{array}$ & 0.06 \\
\hline All & VEGF percentage & $\begin{array}{l}\text { Lower tercile } \\
\text { Middle tercile } \\
\text { Higher tercile }\end{array}$ & $\begin{array}{l}24 \\
27 \\
30\end{array}$ & $\begin{array}{l}1579 \\
1289 \\
1615\end{array}$ & 0.55 \\
\hline All & VEGF intensity & $\begin{array}{l}\text { Score } 1 \\
\text { Score } 2 \\
\text { Score } 3\end{array}$ & $\begin{array}{r}6 \\
51 \\
24\end{array}$ & $\begin{array}{l}2038 \\
1414 \\
1539\end{array}$ & 0.47 \\
\hline All & VEGF final score & $\begin{array}{l}<\text { Median } \\
\geqslant \text { Median }\end{array}$ & $\begin{array}{l}40 \\
41\end{array}$ & $\begin{array}{l}1713 \\
1294\end{array}$ & 0.12 \\
\hline All & VEGF final score & $\begin{array}{l}\text { Lower tercile } \\
\text { Middle tercile } \\
\text { Higher tercile }\end{array}$ & $\begin{array}{l}24 \\
27 \\
30\end{array}$ & $\begin{array}{l}1579 \\
1459 \\
1458\end{array}$ & 0.88 \\
\hline All & Vascularity & $\begin{array}{l}<\text { Median } \\
\geqslant \text { Median }\end{array}$ & $\begin{array}{l}38 \\
43\end{array}$ & $\begin{array}{l}1297 \\
1680\end{array}$ & 0.20 \\
\hline SCC & VEGF percentage & $\begin{array}{l}<\text { Median } \\
\geqslant \text { Median }\end{array}$ & $\begin{array}{l}28 \\
34\end{array}$ & $\begin{array}{l}1823 \\
1404\end{array}$ & 0.14 \\
\hline SCC & Vascularity & $\begin{array}{l}<\text { Median } \\
\geqslant \text { Median }\end{array}$ & $\begin{array}{l}29 \\
33\end{array}$ & $\begin{array}{l}1306 \\
1844\end{array}$ & 0.11 \\
\hline Stage I & VEGF percentage & $\begin{array}{l}<\text { Median } \\
\geqslant \text { Median }\end{array}$ & $\begin{array}{l}24 \\
21\end{array}$ & $\begin{array}{l}1884 \\
1605\end{array}$ & 0.33 \\
\hline Stage I & Vascularity & $\begin{array}{l}<\text { Median } \\
\geqslant \text { Median }\end{array}$ & $\begin{array}{l}20 \\
25\end{array}$ & $\begin{array}{l}1853 \\
1675\end{array}$ & 0.65 \\
\hline Stage II + IIIa & VEGF percentage & $\begin{array}{l}<\text { Median } \\
\geqslant \text { Median }\end{array}$ & $\begin{array}{l}14 \\
22\end{array}$ & $\begin{array}{r}1543 \\
946\end{array}$ & 0.17 \\
\hline Stage II + IIIa & Vascularity & $\begin{array}{l}<\text { Median } \\
\geqslant \text { Median }\end{array}$ & $\begin{array}{l}18 \\
18\end{array}$ & $\begin{array}{r}674 \\
1685\end{array}$ & $0.01^{\star}$ \\
\hline
\end{tabular}

*Significant difference.

SCC, squamous cell carcinoma. 


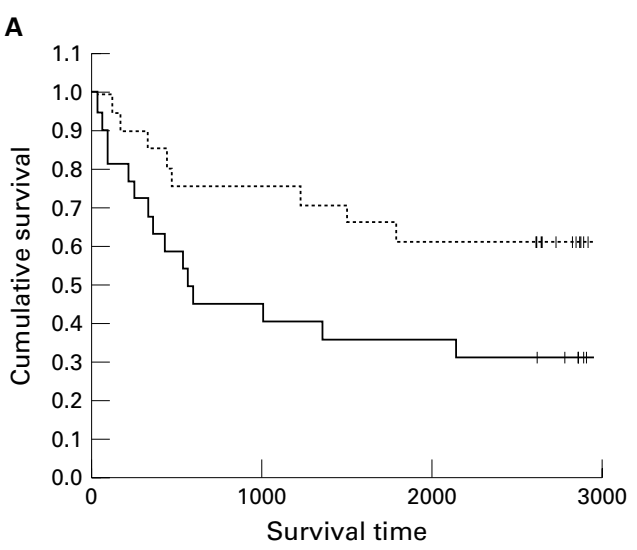

B

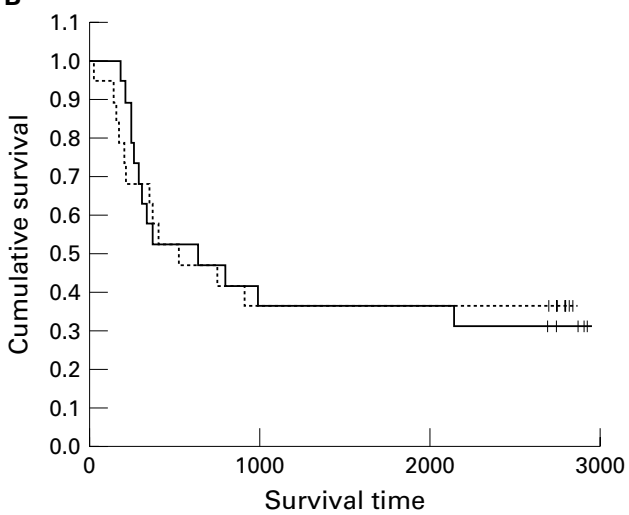

Figure 2 Kaplan-Meier survival curves for patients divided according to their vascularity and vascular endothelial growth factor (VEGF) expression. Average microvascular density and VEGF percentage were divided by the median. (A) Patients with high vascularity: solid line, high VEGF; dashed line, low VEGF; +, censored. Log rank test, $p=0.025$. (B) Patients with low vascularity: solid line, high VEGF; dashed line, low VEGF; +, censored. Log rank test, $p=0.692$.

vascularity and low VEGF ( $\mathrm{n}=20)$, (3) low vascularity and high VEGF $(n=20)$, and $(4)$ low vascularity and low VEGF $(\mathrm{n}=18)$. Figure 2 shows the Kaplan-Meier survival analysis for these four groups of patients. Comparisons by log rank tests indicated that, among patients with high vascularity, those with low VEGF had significantly improved survival compared with those with high VEGF ( $p=0.025$ ) (fig 2A). In contrast, low VEGF expression did not confer a survival advantage in patients with low vascularity $(p=0.69)$ (fig $2 B$ ). Patients with high vascularity and low VEGF also showed improved survival compared with those with low vascularity and high VEGF $(p=0.02)$. The same results were obtained using VEGF final score. VEGF intensity was not divided into these four groups because of the small number of specimens with an intensity of 1 or 3 .

\section{Discussion}

In tumour sections, VEGF mRNA has been localised by in situ hybridisation to the tumour cells, fibroblasts, and some inflammatory cells, but not to endothelial cells. ${ }^{82627}$ However, using immunohistochemistry, VEGF protein has been found in endothelial cells, ${ }^{12}{ }^{17} 27$ as well as in the tumour and other cells expressing VEGF mRNA. ${ }^{8728}$ These results suggest an angiogenic role for VEGF in various types of tumour, including NSCLC. Our results are in general agreement with previous reports regarding the immunolocalisation of VEGF in lung tumour cells. Unlike Fontanini et al, ${ }^{8}$ but in agreement with others, ${ }^{12}{ }^{17} 27$ we found positive staining in endothelial and other stromal cells. Because VEGF is a potent angiogenic factor, its expression in lung tumours can be expected to be correlated directly with the vascularity of the tumour, assuming that vascularity is an index of angiogenesis. Such correlation has, in fact, been found in some studies, but not in others. We found no association between vascularity and VEGF expression, lending support to our previous data indicating that vascularity, assessed with pan-endothelial antibodies, does not necessarily represent angiogenesis in lung and breast tumours. ${ }^{22} 2325$

There is lack of consensus regarding the value of either vascularity (reviewed by Decaussin and colleagues ${ }^{12}$ and Chandrachud and colleagues $^{22}$ ) or VEGF expression as tumour prognostic markers in NSCLC. We have previously suggested that discrepancies among studies might be the result of tumour heterogeneity ${ }^{25}$ or differences in the methodology used. ${ }^{23}$ For example, the method used to unmask epitopes in paraffin wax embedded sections can change the vascularity ranking among tumours, as well as the difference in vascularity between peritumour and intratumour stroma. ${ }^{23}$ After immunolocalisation, the expression of VEGF has been evaluated by various means, including the percentage of cells stained, ${ }^{7-9}$ intensity, ${ }^{29}$ and a combination of these. ${ }^{611}{ }^{17}$ The percentage of cells stained is the most commonly used method, but cut off values taken to define high and low VEGF expression have varied from $5 \%{ }^{30}$ to $70 \%{ }^{10}$ In our study, we obtained similar results using three indices of VEGF (percentage, intensity, final score). However, in oral tissues, discrepancies regarding VEGF expression have been observed when using different VEGF indices or antibodies. These results highlight the need to standardise the methodology and determine the presence of specific VEGF isoforms in the tissues examined ( $R$ Baillie et al, 2000, unpublished data).

As found previously with a larger number of patients, ${ }^{22}$ high vascularity tended to be associated with improved survival times, although the difference was not significant for most groups of patients (table 2). Our findings are consistent with the hypothesis that in large tumours, such as most resected NSCLCs, low vascularity results when a highly aggressive tumour grows at a faster rate than its vasculature, reflecting poor prognosis. In contrast, low vascularity in small or nascent tumours may reflect low angiogenic potential and good prognosis.

Various studies have found high VEGF expression to be associated with poor survival time in lung tumours. Although we found a similar trend, the difference was not significant for the full cohort of patients, or when analysed separately according to tumour type or stage. Interestingly, high VEGF expression was associated with poor survival in patients with high 
vascularity (fig $2 \mathrm{~A}$ ), but had no discriminant value among patients with low vascularity (fig 2B). In a similar way, Mattern and colleagues ${ }^{32}$ subdivided 87 patients with NSCLC into four groups according to low and high vascularity and proliferation. They found that a subgroup with low vascularity and high proliferation was characterised by high VEGF expression, increased incidence of metastases, and short survival times. Although these results and ours need to be confirmed with a larger number of patients, they suggest that the combination of VEGF and vascularity has prognostic value in NSCLC.

The antibody used in our study has been used previously to demonstrate high VEGF expression in mesotheliomas, in comparison with the low expression detected in adjacent normal tissues. ${ }^{20}$ In our study, this antibody strongly stained the normal bronchial epithelium adjacent to tumours as well as other normal stromal cells (fig 1). Apart from being present in tumours, VEGF has been localised in various normal tissues, being particularly abundant in lung. ${ }^{33}{ }^{34}$ These findings indicate that VEGF may play a physiological role in this tissue.

We thank the Roy Castle Lung Cancer Foundation, The Tayside Area Oncology Fund, and the Anonymous Trust for financial support. We also thank Dr MW Myskow (Department of Histopathology, Cardiothoracic Centre and Broadgreen Hospital, Liverpool) for providing the tissue specimens, and Mr G Carmichael and Mrs M Thompson (Oral Diseases Group, Dental School, Dundee University) for excellent technical assistance.

1 Folkman J, Shing Y. Angiogenesis. f Biol Chem 1992;267:10931-4.

2 Ferrara N. Role of vascular endothelial growth factor in the regulation of angiogenesis. Kidney Int 1999;56:794-814

$3 \mathrm{Kim} \mathrm{KJ}$, Li B, Armanini M, et al. Inhibition of vascular endothelial growth factor-induced angiogenesis suppresses tumour growth in vivo. Nature 1993;362:841-4.

4 Benjamin LE, Golijanin D, Itin A, et al. Selective ablation of immature blood vessels in established human tumors follows vascular endothelial growth factor withdrawal. follows vascular endothelial

5 Volm M, Koomagi R, Mattern J. Prognostic value of vascular endothelial growth factor and its receptor Flt-1 in squamous cell lung cancer. Int f Cancer 1997;74:64-8

6 Volm M, Rittgen W, Drings P. Prognostic value or ERBB-1, VEGF, cyclin A, FOS, JUN and MYC in patients with squamous cell lung carcinomas. Br f Cancer 1998;77:6639.

7 Fontanini G, Boldrini L, Vignati S, et al. Bc12 and p53 regulate vascular endothelial growth factor (VEGF)-mediated angiogenesis in non-small cell lung carcinoma. Eur f Cancer 1998;34:718-23.

8 Fontanini G, Vignati S, Lucchi M, et al. Neoangiogenesis and $\mathrm{p} 53$ protein in lung cancer: their prognostic role and their relation with vascular endothelial growth factor their relation with vascular endothelial growth

9 Giatromanolaki A, Koukourakis MI, Kakolyris S, et al. Vascular endothelial growth factor, wild-type p53, and cular endothelial growth factor, wild-type p53, and angiogenesis in early operable no

10 O'Byrne KJ, Koukourakis MI, Giatromanolaki a, et al. Vascular endothelial growth factor, platelet-derived endothelial cell growth factor and angiogenesis in non-small-cell lung cancer. Br f Cancer 2000;82:1427-32.

11 Shibusa T, Shijubo N, Abe S. Tumor angiogenesis and vascular endothelial growth factor expression in stage I lung adenocarcinoma. Clin Cancer Res 1998;4:1483-7.
12 Decaussin M, Sartelet H, Robert C, et al. Expression of vascular endothelial growth factor (VEGF) and its two receptors (VEGF-R1-Flt1) and (VEGF-R2-Flk/KDR) in nonsmall cell lung carcinomas (NSCLC): correlation with
angiogenesis and survival. $\mathcal{F}$ Pathol 1999;188:369-77.

13 Takahama M, Tsutsumi M, Tsujiuchi T, et al. Frequent expression of the vascular endothelial growth factor in human non-small-cell lung cancers. fpn f Clin Oncol 1998; 28:176-81.

14 Salven P, Ruotsalainen T, Mattson K, et al. High pre-treatment serum level of vascular endothelial growth factor (VEGF) is associated with poor outcome in small-cell lung cancer. Int 7 Cancer 1998;79:144-6.

15 Brattstrom D, Bergqvist M, Larsson A, et al. Basic fibroblast growth factor and vascular endothelial growth factor in sera from non-small cell lung cancer patients. Anticancer Res 1998;18:1123-7.

16 Takigawa N, Segawa Y, Fujimoto N, et al. Elevated vascular endothelial growth factor levels in sera of patients with lung cancer. Anticancer Res 1998;18:1251-4.

17 Mattern J, Koomagi R, Volm M. Association of vascular endothelial growth factor expression with intratumoral microvessel density and tumour cell proliferation in human epidermoid lung carcinoma. Br f Cancer 1996;73:931-4.

18 Takanami I, Tanaka F, Hashizume T, et al. Vascular endothelial growth factor and its receptor correlate with angiogenesis and survival in pulmonary adenocarcinoma. Anticancer Res 1997;17:2811-14.

19 De Jong JS, Van Diest PJ, Van Der Walk P, et al. Expression of growth factors, growth-inhibiting factors, and their receptors in invasive breast cancer. II: correlations with proliferation and angiogenesis. F Pathol 1998;184:53-7.

20 Kumar-Singh S, Weyler J, Martin MJH, et al. Angiogenic cytokines in mesothelioma: a study of VEGF, FGF-1 an

21 Jefferson MF, Pendleton N, Faragher EB, et al. Tumour volume as a predictor of survival after resection of non-small

22 Chandrachud LM, Pendleton N, Chisholm DM, et al. Relationship between vascularity, age and survival in non-smallcell lung cancer. Br 7 Cancer 1997; 76:1367-75.

23 Schor AM, Pendleton N, Pazouki S, et al. Assessment of vascularity in histological sections: effects of methodology and value as an index of angiogenesis in breast tumours. Histochem F 1998;30:849-56.

24 Jarret DB, Roth J, Kahn CR, et al. Direct method for detection and characterisation of cell surface receptors for insulin by means of 125I-labelled autoantibodies against the insulin receptor. Proc Natl Acad Sci U S A 1976;73:411519.

25 Schor AM, Pazouki S, Morris J, et al. Heterogeneity in microvascular density in lung tumours: comparison with normal bronchus. Br f Cancer 1998;77:946-51.

26 Abu-Jawdeh GM, Faix JD, Niloff J, et al. Strong expression of vascular permeability factor (vascular endothelial growth factor) and its receptors in ovarian borderline and malignant neoplasms. Lab Invest 1996;74:1105-15.

27 Brown LF, Guidi, AJ, Schnitt, SJ, et al. Vascular permeability factor/vascular endothelial growth factor and vascular stroma formation in neoplasia: insights from in situ hybridisation studies. F Histochem Cytochem 1998;46:56975.

28 Ohta Y, Watanabe Y, Murakami S, et al. Vascular endothelial growth factor and lymph node metastases in primary lung growth factor and lymph node metast

29 Moriyama M, Kumagai S, Kawashiri S, et al. Immunohistochemical study of tumour angiogenesis in oral squamous cell carcinoma. Oral Oncol 1997;33:369-74.

30 Imoto H, Osaki T, Taga S, et al. Vascular endothelial growth factor expression in non-small-cell lung cancer: prognostic significance in squamous cell carcinoma. 7 Thorac Cardiovasc Surg 1998;115:1007-14.

31 Maeda T, Matsumura S, Hiranuma $\mathrm{H}$, et al. Expression of vascular endothelial growth factor in human oral squamous cell carcinoma: its association with tumour progression and p53 gene status. $\mathcal{F}$ Clin Pathol 1998;51:771-5.

32 Mattern J, Koomagi R, Volm M. Biological characterization of subgroups of squamous cell lung carcinomas. Clin Canof subgroups of squamous
cer Res 1999;5:1459-63.

33 Fehrenbach H, Kaspar M, Haase M, et al. Differential immunolocalisation in rat and human adult lung, and in experimental rat lung fibrosis: light, fluorescence, and elecron microscopy. Anat Rec 1999;254:61-73.

34 Berse B, Brown LF, Van de Water L, et al. Vascular permeability factor (vascular endothelial growth factor) gene is expressed differentially in normal tissues macrophages and tumours. Mol Biol Cell 1992;3:211-20. 